Original Research Article

\title{
Effect of atorvastatin and rosuvastatin on glucose intolerance in low dose streptozotocin induced hyperglycemic Albino rats
}

\author{
Manju Gari, Abhishek Kumar, Lakhan Majhee*
}

Department of Pharmacology, Rajendra Institute of Medical Sciences (RIMS), Ranchi, Jharkhand, India

Received: 02 May 2017 Accepted: 27 May 2017

*Correspondence to: Dr. Lakhan Majhee, Email:drlakhan35@gmail.com

Copyright: (C) the author(s), publisher and licensee Medip Academy. This is an openaccess article distributed under the terms of the Creative Commons Attribution NonCommercial License, which permits unrestricted noncommercial use, distribution, and reproduction in any medium, provided the original work is properly cited.

\begin{abstract}
Background: Dyslipidemia and glucose intolerance are closely associated with each other especially as a part of metabolic syndrome. Statins are the drug of choice for treatment of dyslipidemia and for primary prevention of coronary heart disease in diabetics. Recent studies indicate risk of new onset diabetes in patients receiving statins. Hence it was worthwhile to study the effect of two most commonly used statins, which differ in their lipophilicity, on glucose tolerance in prediabetic animal model.

Methods: The study consisted of 3 groups with 6 wistar rats in each and hyperglycemia was induced by intraperitoneal injection of low dose $(25 \mathrm{mg} / \mathrm{kg})$ streptozotocin. Group 1 served as control, group 2 and 3 were given Atorvastatin and Rosuvastatin respectively for 8 weeks. Oral glucose tolerance test (OGTT) was performed at 0,1 and $2 \mathrm{hrs}$ after glucose load on days 0,14 , 28, 42 and 56 days.

Results: Starting from $28^{\text {th }}$ day onwards both the treatment groups showed progressive worsening of glucose tolerance throughout the study period in comparison to the control. The impairing effect on glucose tolerance was less pronounced in Rosuvastatin group as compared to Atorvastatin.

Conclusions: Hydrophilic Rosuvastatin showing less impairing effect on glucose tolerance can be a rational choice than lipophilic Atorvastatin for prevention and control of dyslipidemia in patients at risk of developing frank diabetes or having impaired glucose tolerance.
\end{abstract}

Keywords: Atorvastatin, Glucose tolerance, Hydrophilic, Rosuvastatin, Streptozotocin

\section{INTRODUCTION}

An important modifiable risk factor for the development of atherosclerosis and cardiovascular disease (CVD) is Dyslipidemia. ${ }^{1}$ The prevalence of dyslipidemia is steadily rising in developing countries. ${ }^{2}$ Effective management of dyslipidemia by pharmacological treatment is known to reduce the rate of CVD morbidity and mortality. ${ }^{3}$ Statins, the main drugs used for treatment of dyslipidemia, are 3Hydroxy-3-methylglutaryl coenzyme A (HMG-CoA) reductase competitive inhibitors which catalyze an early, rate-limiting step in cholesterol biosynthesis. ${ }^{4}$
Diabetes manifests itself typically in the context of other abnormalities, especially the principal components of metabolic syndrome, namely hypertension and hyperlipidemia. ${ }^{5}$ Metabolic syndrome is often associated with prediabetes i.e. Impaired fasting glucose (IFG) and/or Impaired glucose tolerance (IGT). ${ }^{6}$ During the prediabetic state also, the risk of a CVD event is modestly increased. $^{7}$

The transition from prediabetes to diabetes usually results from failure of compensatory mechanisms especially defects in insulin secretion. Even transient impaired glucose tolerance may be associated with an increased 
risk of deterioration to diabetes. ${ }^{8}$ Diabetes mellitus is considered to be a CVD-equivalent disorder. So dyslipidemia treatment guidelines is the same as that for patients with established. ${ }^{4}$

Although statins are the cornerstone of lipid-altering therapy for reducing CVD risk in diabetics and nondiabetics, recent studies have suggested that statins cause worsening of blood glucose profile and increase the risk of diabetes..$^{9-12}$ Two meta-analyses of available randomized placebo-controlled trials-HPS (simvastatin 40mg), LIPID (pravastatin 40mg), ASCOT (atorvastatin $10 \mathrm{mg}$ ), CORONA (rosuvastatin 10mg), and JUPITER (rosuvastatin 20mg) showed a slight increase in the risk of diabetes. ${ }^{10,13}$

All statins are similar in mode of action and their potency being comparable in reducing low density lipoprotein (LDL) Cholesterol; however, they show difference in their pleotropic effects- attributable to marked differences in lipophilicity. ${ }^{14}$ The presence or absence of polar moieties on their largely hydrophobic structures influence solubility and localisation due to which metabolic differences among the statins occur. ${ }^{15,16}$

Atorvastatin, fluvastatin, pitavastatin, simvastatin, cerivastatin and lovastatin are lipophilic, while pravastatin and rosuvastatin are hydrophilic. ${ }^{16}$

Hydrophilic statins are more hepatocyte specific and less likely to enter extrahepatic cell membranes such as $\beta$ cells of pancreas, adipocytes or skeletal muscles whereas lipophilic statins can more readily penetrate these tissues therefore it has been hypothesized that the latter might be more diabetogenic. ${ }^{17}$ Lipophilic statins enter into cells by passive diffusion, whereas hydrophilic statins employ carrier-mediated mechanisms for uptake. ${ }^{17}$ Lipophilic statins may be incorporated into various organs such as pancreas, adipose tissue and muscle which are important for glucose metabolism, while hydrophilic statins are incorporated mainly into liver.

A small excess percentage of those taking statins may develop diabetes but the benefits from reduction in cardiovascular events due to their use overweigh the risk of development of diabetes; and so, this effect do not change the recommendation of use of statins in CVD. ${ }^{18}$ Hence it was worthwhile to study the effect of two most commonly used statins (Atorvastatin and Rosuvastatin), which differ in their lipophilicity, on glucose tolerance in prediabetic (hyperglycaemic) animal model.

\section{METHODS}

This was an animal experimental study done in the Animal Laboratory of Department of Pharmacology, RIMS, Ranchi. The total study period was 8 weeks (56 days). Only healthy and active rats weighing 200-250gms with random blood sugar i.e. 140-199mg/dl (Impaired glucose tolerance range) were included. The diabetic animals were allowed free access to tap water, standard laboratory pellet diet along with added fat (butter) and glucose, and were kept at room temperature and optimum humidity in their cages.

\section{Drugs}

1. Atorvastatin [Storvas 20mg tablet- Ranbaxy (Cardiovasculars)] (1.8mg/kg body wt).

2. Rosuvastatin [Rosuvas 10mg tablet - Ranbaxy] (0.9 mg/kg body wt)

\section{Dose calculation}

On the basis of body surface area: Surface area ratio of $200 \mathrm{~g}$ rat to $70 \mathrm{~kg}$ man is 0.018 (conversion factor for rat). Thus, human dose of any drug (for a $70 \mathrm{~kg}$ person) multiplied by 0.018 gives the value of that drug for $200 \mathrm{~g}$ of rat. Multiplying the product with 5 gives $\mathrm{mg} / \mathrm{kg}$ value. $^{19}$

\section{Induction of hyperglycemia}

Rats were fasted for 12 hours overnight before inducing $\beta$ cell destruction. Freshly prepared streptozotocin (STZ) solution in $0.1 \mathrm{M}$ citrate buffer $(\mathrm{pH} \mathrm{4.2)}$ was used for a single intra-peritoneal injection of $25 \mathrm{mg} / \mathrm{kg}$ (i.e., about half the diabetes induction dose) of streptozotocin. After 3 days of stabilization period oral administration of statins and Normal Saline (with the help of gavage feeding tube) was started and continued on once a day basis at a fixed time for 8 weeks

\section{Sample size}

18 male Wistar (albino) rats were divided into 3 groups having 6 rats each (Table 1 ).

Table 1: Grouping of rats.

\begin{tabular}{|lll|}
\hline Groups & All (STZ) induced & Drugs \\
\hline Group 1 & Hyperglycemic control & $\begin{array}{l}\text { Given normal } \\
\text { saline }\end{array}$ \\
\hline Group 2 & Hyperglycemic treated & With atorvastatin \\
\hline Group 3 & Hyperglycemic treated & With rosuvastatin \\
\hline
\end{tabular}

\section{Oral glucose tolerance test}

Oral glucose tolerance test (OGTT) was performed after oral administration of $0.5 \mathrm{~g} / \mathrm{ml}$ glucose solution at $1 \mathrm{ml} / 100 \mathrm{~g}$ body weight $(5 \mathrm{~g} / \mathrm{kg})$ to an overnight-fasted conscious rat through a gavage tube. ${ }^{20}$ Blood glucose was measured just before glucose load ( 0 hour) and after 1 and 2 hours of glucose load. Oral glucose tolerance test was performed in all groups on day $0,14^{\text {th }}, 28^{\text {st }}, 42^{\text {th }}$ and $56^{\text {th }}$ day of starting statin administration. The blood sample were taken from tail vein of rats and were estimated by a glucose oxidation method. 


\section{Statistical analysis}

Data were expressed as Mean \pm Standard deviation. Data were analysed with IBM-SPSS version 23 software. Statistical comparisons were performed by one-way ANOVA followed by Post hoc Multiple Comparison Tukey HSD (Honestly significant difference) Test. Values were considered statistically significant when $\mathrm{P}$ $<0.05$.

\section{RESULTS}

Table 2 shows Mean \pm SD data representation of hour ' 0 ' for all three groups throughout 8 weeks of study period.
The OGTT values were higher than normal range in all groups. The value did not change appreciably throughout in group 1. But treatment groups 2 and 3 showed a rising trend as the study progressed from 28 days onwards. The rise in values differed in both treated groups. The increase in blood glucose values in 0 hours was higher in Atorvastatin group than Rosuvastatin.

Table 3 shows data of hour ' 1 ' for all the groups throughout 56 days of study. The value did not change appreciably from day 0 throughout in group 1. But treatment groups i.e. 2 and 3 showed a rising trend as the study progressed from $4^{\text {th }}$ week onwards. Both statin treated groups showed difference in rise of blood glucose.

Table 2: Hour "0" data of all the groups throughout the study period (Mean \pm SD).

\begin{tabular}{|llllll|}
\hline Hour 0 & Day 0 & Day 14 & Day 28 & Day 42 & Day 56 \\
\hline & Mean \pm SD & Mean \pm SD & Mean \pm SD & Mean \pm SD & Mean \pm SD \\
\hline Group 1 & $104.16 \pm 1.47$ & $104.00 \pm 2.36$ & $104.16 \pm 1.47$ & $104.50 \pm 2.42$ & $104.16 \pm 2.63$ \\
\hline Group 2 & $105.16 \pm 1.47$ & $105.50 \pm 2.42$ & $117.00 \pm 1.41$ & $119.16 \pm 1.47$ & $122.33 \pm 1.21$ \\
\hline Group 3 & $105.83 \pm 2.48$ & $105.33 \pm 1.21$ & $110.00 \pm 1.41$ & $113.66 \pm 1.63$ & $118.66 \pm 1.63$ \\
\hline
\end{tabular}

Table 3: Hour "1" data of all the groups throughout the study period (Mean \pm SD).

\begin{tabular}{|llllll|}
\hline Hour 1 & Day 0 & Day 14 & Day 28 & Day 42 & Day 56 \\
\hline & Mean \pm SD & Mean \pm SD & Mean \pm SD & Mean \pm SD & Mean \pm SD \\
\hline Group 1 & $171.16 \pm 5.63$ & $171.83 \pm 6.43$ & $171.33 \pm 7.25$ & $171.16 \pm 5.91$ & $171.33 \pm 6.02$ \\
\hline Group 2 & $171.83 \pm 2.78$ & $171.66 \pm 5.71$ & $198.16 \pm 2.31$ & $210.16 \pm 2.31$ & $222.83 \pm 3.54$ \\
\hline Group 3 & $171.33 \pm 2.87$ & $171.83 \pm 3.65$ & $188.50 \pm 1.87$ & $198.33 \pm 2.16$ & $209.00 \pm 2.60$ \\
\hline
\end{tabular}

Table 4: Hour "2" data of all the groups throughout the study period (Mean \pm SD).

\begin{tabular}{|llllll|}
\hline Hour 2 & Day 0 & Day 14 & Day 28 & Day 42 & Day 56 \\
\hline & Mean \pm SD & Mean \pm SD & Mean \pm SD & Mean \pm SD & Mean \pm SD \\
\hline Group 1 & $146.66 \pm 2.80$ & $147.00 \pm 4.81$ & $146.83 \pm 3.06$ & $147.16 \pm 2.78$ & $147.66 \pm 2.58$ \\
\hline Group 2 & $147.00 \pm 2.60$ & $147.16 \pm 2.04$ & $167.50 \pm 1.87$ & $176.83 \pm 2.31$ & $187.50 \pm 1.87$ \\
\hline Group 3 & $147.16 \pm 2.40$ & $147.50 \pm 3.27$ & $165.16 \pm 3.31$ & $172.33 \pm 2.16$ & $179.50 \pm 1.87$ \\
\hline
\end{tabular}

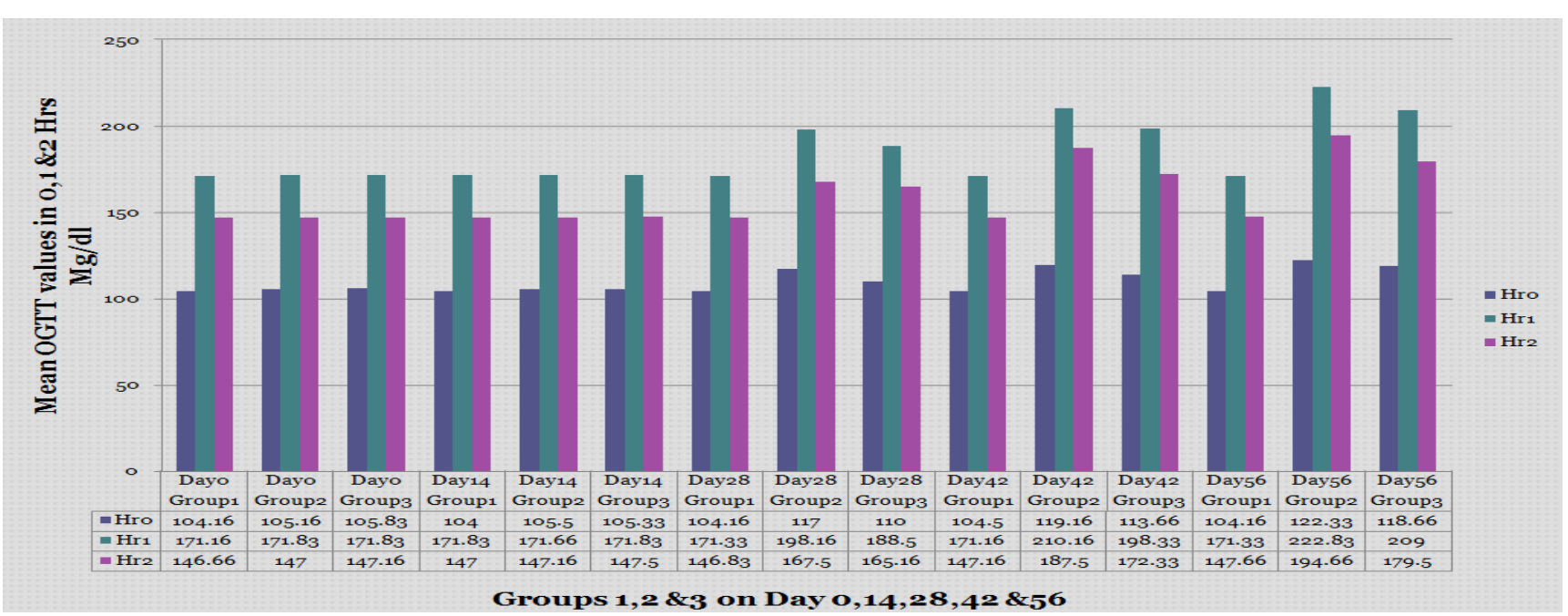

Figure 1: Comparison of 0, 1 and 2 hr OGTT of all groups throughout the study period. 
In Table 4 also the values were higher than normal range. The value did not change appreciably throughout in group 1. But treatment groups i.e. Atorvastatin and Rosuvastatin showed increment as the study progressed from 28 days onwards, however there was no significant difference in values between group 2 and 3 at $28^{\text {th }}$ day. It also shows that the increase in mean blood glucose values in 2 hours was higher in group treated with atorvastatin than in rosuvastatin from 42 days onwards.

Figure 1 gives the comparison between groups. The values for 0,1 and 2 hours glucose levels were higher than normal range in group 1 but this group had negligible changes in OGTT as the study progressed. The values on 0 and $14^{\text {th }}$ day of 2 and 3 groups were similar to that of group 1 (hyperglycaemic control). It indicates that the effect of statins on glucose metabolism was not apparent till 2 weeks but took 4 weeks to show their effects. There were significant differences in values in all hours between groups from $28^{\text {th }}$ day onwards except $2 \mathrm{hr}$ value on $28^{\text {th }}$ day between group 2 and 3 .

\section{DISCUSSION}

We have chosen low dose of streptozotocin $(25 \mathrm{mg} / \mathrm{dl})$ I.P to produce prediabetic state in rats i.e. by partial $\beta$ cell destruction. The effect of statins on glucose tolerance in full dose $(50-60 \mathrm{mg} / \mathrm{dl}) \mathrm{STZ}$ induced diabetic model rats, the diabetes induced may be too severe to detect mild influence of a drug on the glucose tolerance as observed by Makoto Kanda, Kumi Satoh, and Kazuo Ichihara. ${ }^{21}$

Ganda et al, have demonstrated a progressive increase in mean plasma glucose following administration of streptozotocin greater than $20 \mathrm{mg} / \mathrm{kg}$. The blood glucose and OGTT-induced increase in the glucose were progressively increased depending on the dose of streptozotocin (which gives a sigmoid curve). ${ }^{22}$

It seems that not only the glucose tolerance after a glucose load was affected but also the corresponding fasting levels ( $0 \mathrm{hrs})$ were also impaired both the instead of all statin treated groups. It means both muscle (IGT) and hepatic (IFG) insulin resistance may have been impaired. Moreover, both the first and early (IFG) and late phase (IGT) of insulin secretion might have been defective. Ding et al, in 2009 observed no change in fasting plasma glucose after treatment with atorvastatin (10mg-40mg) in 27 individuals compared to 21 controls. $^{23}$

SPARCL (atorvastatin) study in 2006 and JUPITER (rosuvastatin) study in 2008 demonstrated a significant increase in the incidence of diabetes in patients on atorvastatin $(8.71 \%)$ and rosuvastatin $(3.0 \%)$ respectively compared to placebo. ${ }^{24,25}$ The higher incidence with atorvastatin as compared to rosuvastatin supports our findings. Coleman et al, and Ratpathak et al, in their respective meta-analyses of RCTs HPS (simvastatin), LIPID (pravastatin), ASCOT (atarvastatin), JUPITER (rosuvastatin) and CORONA (rosuvastatin) found that there was increased risk of diabetes with these statins which is coherent with our study. ${ }^{10,13}$ Sattar N, Preiss D, Murray HM et al, meta-analysed through pooled data from 13 trials between 1994 and 2009 revealed statin therapy was associated with a $9 \%$ increased risk of diabetes. ${ }^{11,12}$ However their analysis differed from ours in the fact that Rosuvastatin was found to be most diabetogenic followed in sequence by atorvastatin.

Statins are known to modulate insulin secretion and sensitivity through various mechanisms which are as follows: ${ }^{26-28}$

The possible hypotheses through which the statins increased hyperglycemia may have involved both decreased insulin secretion and increased insulin resistance. The insulin secretion may be decreased (in both lipophilic and hydrophilic statins) due to proposed mechanisms like statin induced inhibition of the glucose induced cytosolic $\mathrm{Ca}^{2+}$ signaling and insulin secretion by blocking L-type $\mathrm{Ca}^{2+}$ channels in $\beta$ cells (more with lipophilic statins); chronic cholesterol depletion causing dysregulation of SNARE proteins in pancreatic $\beta$ cells and inhibition of the voltage gated $\mathrm{Ca}^{2+}$ channels and also inhibiting the activity of glucokinase the rate- limiting enzyme for intracellular glucose metabolism; the interplay between inflammation, oxidation, and apoptosis- all potentially triggered by increased abundance of plasma-derived LDL-cholesterol due to statin-induced blockade of de-novo cholesterol synthesis; interference with $\beta$ cell insulin secretion by interfering with isoprenylation of guanosine triphosphate (GTP) binding proteins; and statin inhibited HMGCoA reductase suppression of synthesis of ubiquinone (CoQ), an essential factor in the mitochondrial electron transfer system, resulting in inhibition of insulin secretion due to reduced production of ATP.

The possible mechanisms through which statins (mainly lipophilic Atorvastatin) may have increased insulin resistance due to suppressed synthesis of isoprenoids causing downregulation of Glut-4 expression on skeletal muscles and adipocyte cells, leading to impaired glucose uptake; statin-induced cholesterol lowering per se contributing to myocyte damage of skeletal muscle fibre causing skeletal muscle insulin resistance; statin induced myalgia and fatigue may impair exercise capacity and aggravate sarcopenia, which is associated with impaired glucose intolerance; depletion of CoQ10 and subsequent mitochondrial damage in skeletal muscles and adipocytes limiting their glucose uptake; decrease in adiponectin (an insulin sensitizing cytokine released from adipocytes) levels by Rosuvastatin.

\section{CONCLUSION}

To conclude, both atorvastatin and rosuvastatin have impairing effects on glucose tolerance. Both atorvastatin and rosuvastatin also have impairing effects on fasting 
blood glucose. Hydrophilic rosuvastatin had better effect on glucose tolerance and fasting blood glucose than the lipophilic atorvastatin. So, if statins have to be used Rosuvastatin and not atorvastatin may be a rational choice in patients with risk of hyperglycemia.

\section{ACKNOWLEDGMENTS}

Authors would like to thank all the laboratory staffs, specially the animal attendant, who have assisted in the work and been helpful in keeping the animals in maintained proper laboratory conditions.

\section{Funding: No funding sources}

Conflict of interest: None declared

Ethical approval: The study was approved by the Institutional Animal Ethics Committee of Rajendra Institute of Medical Sciences (RIMS), Ranchi

\section{REFERENCES}

1. Blood pressure, cholesterol, and stroke in eastern Asia: Eastern stroke and coronary heart disease collaborative research group. Lancet 1998;352:18017.

2. Fuentes R, Uusitalo T, Puska P, Tuomilehto J, Nissinen A. Blood cholesterol level and prevalence of hypercholesterolaemia in developing countries: a review of population-based studies carried out from 1979 to 2002. Eur J Cardiovasc Prev Rehabil. 2003;10:411-9.

3. Heart Protection Study Collaborative Group. MRC/BHF Heart Protection Study of cholesterol lowering with simvastatin in 20536 high-risk individuals: a randomised placebo controlled trial. The Lancet. 2002 Jul 6;360(9326):7-22.

4. Bersot TP. Drug therapy for hypercholesterolemia and dyslipidemia. Goodman and Gilman's, The Pharmacological Basis of Therapeutics. McGrawHill. 2011:877-908.

5. Oda E. Metabolic syndrome: its history, mechanisms, and limitations. Acta Diabetol. 2012 Apr;49(2):8995 .

6. Batsis JA, Nieto-Martinez RE, Lopez-Jimenez F. Metabolic syndrome: from global epidemiology to individualized medicine. Clin Pharmacol Ther. 2007 Nov;82(5):509-24.

7. Levitan EB, Song Y, Ford ES, Liu S. Is non-diabetic hyperglycemia a risk factor for cardiovascular disease? A metaanalysis of prospective studies. Arch Intern Med. 2004;164:2147-55.

8. Saad MF, Kowler WC, Pettitt DJ, Nelson RG, Bennett PH. Transient impaired glucose tolerance in Pima Indians: Is it important? $\mathrm{Br}$ Med $\mathrm{J}$. 1988;297:1438-41.

9. Mills EJ, Wu P, Chong G, Ghement I, Singh S, Akl EA, et al. Efficacyand safety of statin treatment for cardiovascular disease: a network meta-analysis of 170, 255 patients from 76 randomized trials. QJM. 2011;104:109-24.
10. Rajpathak SN, Kumbhani DJ, Crandall J, Barzilai N, Alderman M, Ridker PM. Statin therapy and risk of developing type 2 diabetes: a meta-analysis. Diabetes Care. 2009;32:1924-9.

11. Sattar N, Preiss D, Murray HM, Welsh P, Buckley BM, de Craen AJ, et al. Statins and risk of incident diabetes: a collaborative meta-analysis of randomised statin trials. The Lancet. 2010 Mar 5;375(9716):73542.

12. Preiss D, Seshasai SR, Welsh P, Murphy SA, Ho JE, Waters DD, et al. Risk of incident diabetes with intensive-dose compared with moderate-dose statin therapy: a meta-analysis. Jama. 2011 Jun 22;305(24):2556-64.

13. Coleman CI, Reinhart K, Kluger J, White CM. The effect of statins on the development of newonset type 2 diabetes: a metaanalysis of randomized controlled trials. Curr Med Res Opin. 2008;24:1359-62.

14. Tandon V, Bano G, Khajuria V, Parihar A, Gupta S. Pleiotropic effects of statins. Indian $\mathrm{J}$ Pharmacol. 2005;37:77-85.

15. Mason RP, Walter MF, Day CA, Jacob RF. Intermolecular differences of 3-hydroxy-3methylglutaryl coenzyme a reductase inhibitors contribute to distinct pharmacologic and pleiotropic actions. The American journal of cardiology. 2005 Sep 5;96(5):11-23.

16. Bonsu KO, Kadirvelu A, Reidpath DD. Lipophilic versus hydrophilic statin therapy for heart failure: a protocol for an adjusted indirect comparison metaanalysis. Systematic reviews. 2013 Apr 23;2(1):22.

17. Schachter M. Chemical, pharmacokinetic and pharmacodynamic properties of statins: an update. Fundam Clin Pharmacol. 2005;19(1):117-25.

18. Deedwania P, Barter P, Carmena R, Fruchart JC, Grundy SM, Haffner S, et al. Reduction of lowdensity lipoprotein cholesterol in patients with coronary heart disease and metabolic syndrome: analysis of the Treating to New Targets study. The Lancet. 2006 Sep 15;368(9539):919-28.

19. Medhi B, Prakash A. Practical manual of experimental and clinical pharmacology. Jaypee Brothers Medical Publishers; 2010:24.

20. Satoh K, Keimatsu N, Kanda M, Kasai T, Takaguri A, Sun F, et al. HMG-CoA reductase inhibitors do not improve glucose intolerance in spontaneously diabetic Goto-Kakizaki rats. Biological and Pharmaceutical Bulletin. 2005;28(11):2092-5.

21. Makoto K, Satoh K, Ichihara K. Effects of Atorvastatin and Pravastatin on Glucose Tolerance in Diabetic Rats Mildly Induced by StreptozotocinBiol. Pharm. Bull. 2003;26(12):1681-4.

22. Ganda OP, Rossini AA, Like AA. Studies on streptozotocin diabetes. Diabetes. 1976 Jul 1;25(7):595-603.

23. Ding PY, Hsu P, Lu T. Statin Therapy on Insulin Resistance and Plasma Level of Adiponectin in Non Diabetic, Hypercholesterolemic Patients. Acta Cardiol Sin. 2009;25:183-9. 
24. Amarenco P. Stroke Prevention by Aggressive Reduction in Cholesterol Levels (SPARCL) Investigators: High-dose atorvastatin after stroke or transient ischemic attack. $\mathrm{N}$ Engl $\mathrm{J}$ Med. 2006;355:549-59.

25. Ridker PM, Danielson E, Fonseca FA, Genest J, Gotto AM, Kastelein JJ, et al. JUPITER Study Group. Rosuvastatin to prevent vascular events in men and women with elevated C-reactive protein. N Engl J Med. 2008;359:2195-207.

26. Metz SA, Rabaglia ME, Stock JB, Kowluru A. Modulation of insulin secretion from normal rat islets by inhibitors of the post-translational modifications of GTP-binding proteins. Biochem J. 1993;295(Pt 1):31-40.
27. Ohrvall M, Lithell H, Johansson J, Vessby B. A comparison between the effects of gemfibrozil and simvastatin on insulin sensitivity in patients with non-insulin-dependent diabetes mellitus and hyperlipoproteinemia. Metabolism. 1995;44:212-7.

28. Sampson UK, Linton MF, Fazio S. Are statins diabetogenic?. Current opinion in cardiology. Jul 2011;26(4):342-7.

Cite this article as: Gari M, Kumar A, Majhee L. Effect of atorvastatin and rosuvastatin on glucose intolerance in low dose streptozotocin induced hyperglycemic Albino rats. Int J Basic Clin Pharmacol 2017;6:1747-52. 